\title{
Assessment of communication skills
}

Citation for published version (APA):

van der Vleuten, C., van den Eertwegh, V., \& Giroldi, E. (2019). Assessment of communication skills. Patient Education and Counseling, 102(11), 2110-2113. https://doi.org/10.1016/j.pec.2019.07.007

Document status and date:

Published: 01/11/2019

DOI:

10.1016/j.pec.2019.07.007

Document Version:

Publisher's PDF, also known as Version of record

Document license:

Taverne

\section{Please check the document version of this publication:}

- A submitted manuscript is the version of the article upon submission and before peer-review. There can be important differences between the submitted version and the official published version of record.

People interested in the research are advised to contact the author for the final version of the publication, or visit the DOI to the publisher's website.

- The final author version and the galley proof are versions of the publication after peer review.

- The final published version features the final layout of the paper including the volume, issue and page numbers.

Link to publication

\footnotetext{
General rights rights.

- You may freely distribute the URL identifying the publication in the public portal. please follow below link for the End User Agreement:

www.umlib.nl/taverne-license

Take down policy

If you believe that this document breaches copyright please contact us at:

repository@maastrichtuniversity.nl

providing details and we will investigate your claim.
}

Copyright and moral rights for the publications made accessible in the public portal are retained by the authors and/or other copyright owners and it is a condition of accessing publications that users recognise and abide by the legal requirements associated with these

- Users may download and print one copy of any publication from the public portal for the purpose of private study or research.

- You may not further distribute the material or use it for any profit-making activity or commercial gain

If the publication is distributed under the terms of Article $25 \mathrm{fa}$ of the Dutch Copyright Act, indicated by the "Taverne" license above, 


\title{
Assessment of communication skills
}

\author{
Cees van der Vleuten ${ }^{\mathrm{a}, *}$, Valerie van den Eertwegh ${ }^{\mathrm{b}}$, Esther Giroldi ${ }^{\mathrm{a}, \mathrm{c}}$ \\ a Maastricht University, Department of Educational Development and Research, School of Health Professions Education(SHE), Faculty of Health, Medicine and \\ Life Sciences, Maastricht, the Netherlands \\ b Maastricht University, Skillslab, Faculty of Health, Medicine and Life Sciences, Maastricht, the Netherlands \\ ${ }^{\mathrm{c}}$ Maastricht University, Department of Family Medicine, Care and Public, Health Research Institute (CAPHRI), Faculty of Health, Medicine and Life Sciences, \\ Maastricht, the Netherlands
}

\section{A R T I C L E I N F O}

\section{Article history:}

Received 4 June 2019

Accepted 6 July 2019

\section{Keywords:}

Communication

Assessment

Programmatic assessment

\begin{abstract}
A B S T R A C T
Objective: This paper addresses how communication skills can best be assessed. Since assessment and learning are strongly connected, the way communication skills are best learned is also described. Results: Communication skills are best learned in a longitudinal fashion with ample practice in an authentic setting. Confrontation of behavior initiates the learning process and should be supported by meaningful feedback through direct observation. When done appropriately a set of (learned) communication skills become integrated skilled communication, being versatilely used in purposeful goal-oriented clinical communication. The assessment of communication skills should follow a modern approach to assessment where the learning function of assessment is considered a priority. Individual assessments are feedback-oriented to promote further learning and development. The resulting rich information may be used to make progression decisions, usually in a group or committee decision. Conclusion: This modern programmatic approach to assessment fits the learning of skilled communication well.

Practice implications: Implementation of a programmatic assessment approach to communication will entail a major innovation to education.
\end{abstract}

(C) 2019 Elsevier B.V. All rights reserved.

\section{Background}

Communication skills are a firm part of training programs of most health professionals. Communication skills has been included as a main competency in all major competency frameworks used in medical education, like Can-Meds [1], ACGM outcomes project [2] and Good Medical Practice [3]. When training programs teach communication skills, then there is often a need to assess these skills as well. Have certain communication outcomes and skills been reached? Has the training program been effective? Is there a feedback process on learning communication skills? The question is how we should assess communication skills in the most appropriate way. The mantra of "assessment driving learning" is true [4], so the way the assessment is carried out will also determine how communication is learned. However, since assessment and learning are so tightly connected, we need to know how communication skills are being learned before we can

\footnotetext{
* Corresponding author at: Maastricht University, Department of Educational Development and Research, Faculty of Health, Medicine and Life Sciences, P.O. Box 616, 6200 MD Maastricht, the Netherlands.

E-mail address: c.vandervleuten@maastrichtuniversity.nl (C. van der Vleuten).
}

say anything meaningful on how to assess them. Therefore, we will start with discussing the learning of communication skills from an educational perspective. Thereafter we will discuss modern insights into assessment and how those apply to the assessment of communication skills.

\section{Learning communication skills from an educational perspective}

Modern training programs are outcome-based. Outcomes are usually defined in a set of competencies. A competency is the integration of knowledge, skills and attitudes to be able to perform a complex professional challenge [5]. Competency frameworks have been developed in all parts of the world with a purpose to better prepare graduates for the health care of the future [3,6,7]. Training programs are structured to cater these competencies in both undergraduate and postgraduate programs. In all competency frameworks communication is an essential one. From an educational perspective, communication skills are complex behavioral skills. Complex skills are best learned through experiential learning [8]. By practicing in an authentic setting and through feedback this skill is being developed. Experiential learning means learning in the most authentic setting. For earlier stages of training, 
simulation strategies may be used such as role play [9] and simulated patient encounters [10], but ultimately skilled communication is needed and therefore best learned and taught in the authentic setting of the workplace and in a longitudinal way $[11,12]$, preferably across the whole training continuum [13].

We tend to think communication skills are stable entities. While learning them, one gradually increases the generic skill until mastery is achieved. Recent research has shown clearly that communication skills are not stable or generic, but highly contextually specific, all depending on the patient context and the goals to be achieved [14,15]. As with all expertise [16], continuous and deliberate practice in many different contexts will help learning communication skills. Salmon and Young make a distinction between communication skills and skilled communication [17]. Communication is more than a set of communication skills. It should not be learned (and assessed) in an atomistic way. Skilled communication is goal driven, personalized and flexible. How this is learned is described by two researchers who independently came to a rather similar developmental model based on their research $[18,19]$. Van den Eertwegh et al. studied two postgraduate training settings [20]. In the family medicine training setting a lot of attention was paid to learning communication skills. The typical approach was video recording of patient encounters. These encounters were intermittently discussed and assessed by a clinical supervisor. This confronted the residents with their behavior. As a result of this, they became aware of what specific behavior needed improvement. Most clinical supervisors in family medicine were perceived as good role models in communication. More specifically, in this communication rich environment residents were confronted with their communication behavior which made them conscious about these behaviors. This resulted in searching and practicing other behaviors. With increasing practice, the communication behaviors internalized and became their own. Once internalized these communication behaviors became part of the residents' clinical repertoire. When part of the clinical repertoire, strategic communication behaviors were used to achieve desired patient outcomes. Essentially this process described the trajectory from communication skills to skilled communication. The residents also mentioned that checklists used in formal assessments did not promote learning since they do not take the complexity of clinical practice into consideration, may lead to artificial behavior and do not provide residents with rich, meaningful nor constructive feedback. These checklists were often used as a goal instead of as a means to achieve the goal of skilled communicator

In the second postgraduate training setting van den Eertwegh described, surgery, no structural attention was paid to learning communication skills. The surgical residents were however strongly motivated to learn more communication skills, particularly because they saw poor role models and lacked structural, longitudinal teaching, attention and support to know how to improve their own communication skills. Giroldi et al. identified a similar model of residents' communication learning process and studied the role of the clinical supervisor in this process. As a mentor, coach and role model, the supervisor is able to support their residents in becoming skilled communicators by creating impactful experiences, confronting residents with their communication behaviors, stimulating them to reflect on these behaviors and underlying frames of reference, and helping them in identifying alternative behaviors. Particularly in challenging situations, it is known that residents are in need of alternative, authentic communication strategies that fit the specific context at hand, preferably in the form of concrete wording or example sentences [21]. Supervisors can provide such examples, and can stimulate their residents to repeatedly practice, evaluate and refine them in such a manner that they are eventually incorporated into the resident's personal communication repertoire. Lastly, the supervisor is key in creating a safe learning environment so that the resident feels confident to experiment with these alternatives.

What we can learn from these studies is that learning communication is about longitudinal experiential learning in the most authentic setting, where learners are constructively confronted with their behaviors and receive feedback to shape their behavior gradually to skilled communication.

Feedback is essential for learning any complex skill [22]. The literature on feedback in recent years is rich [23] and we learned many lessons. The credibility of the source of feedback relates to the use of feedback and a lot of feedback is poorly given therefore not credible [24]. Feedback should not be a unidirectional stream of information to the learner, but rather a reflective dialogue in which relationships and culture are very important mediators $[25,26]$. An important lesson we learned is that qualitative information is more effective than quantitative information in learning a complex skill $[27,28]$. So, words are more important than scores when learning a complex skill.

In all, communication is a competency that should be longitudinally learned across the whole training continuum in an authentic setting with a lot of practice in many different contexts with regular meaningful feedback. Instead of learning a set of skills, such a learning process will promote skilled communication that is clinically usable in a versatile goal-oriented way. With this in mind, we can now explore assessment strategies.

\section{Assessing communication}

The term "constructive alignment" refers to the alignment of the assessment approach to the educational approach [29]. In case of a misalignment, the assessment approach will prevail and learning might actually be hampered. The insights on how we learn a complex skill such as communication is sketched above, the assessment would be constructively aligned when the assessment would be:

- longitudinally oriented

- as authentic as possible

- provide meaningful feedback

- be able to make valid (pass/fail or promotion) decisions.

These requirements are strongly aligned with a more recent model of assessment called programmatic assessment [30,31]. In this model of assessment, the data gathering on the learner is disconnected from the decision-making. Essential ingredients are:

1) every assessment is but one data-point

2) each data-point is geared towards giving feedback, not towards decision-making (so no pass/fail decisions are given in a single assessment)

3) assessment data is aggregated in a learning dossier such as (an electronic) portfolio

4) to promote self-directed learning and self-assessment, learners have to reflect on assessment data and are coached in doing this by a trusted person who has access to the learning dossier

5) high stake decisions (pass/fail, promotion, graduation) can only be made when sufficient data points are being gathered and triangulated

6) high stake decisions are made in an independent competencecommittee of experts

In programmatic assessment a multitude of different methods are used. The choice of the method is based on the educational justification for using that method in that moment in time and in relation to the rest of the assessment program. Programmatic 
assessment is very suited for assessing complex skills. If we apply it to communication, we can come to a number of concrete recommendations.

Given that communication skills are mostly behavioral, the preferred method of assessment requires direct observation. The most authentic assessment is direct observation in real clinical practice. Direct observation can have multiple formats [32]. The assessor may sit in the clinical event and observe the event directly (for a set of guidelines on how to observe see Kogan et al. [33]). A clinical event may be video recorded and reviewed later on by the learner and others [34]. Communication skills can be assessed over longer periods of time such as in the multisource feedback [35], in which multiple assessors (the learner self, peers, coworkers, supervisors, patients) complete a ( $\mathrm{n}$ online) questionnaire. Feedback consists of aggregated assessor data. When a simulated setting is used for learning communication skills, the assessment may use simulated settings. The most well-known simulated assessment approach is the OSCE. We caution, however, that the OSCE is a simulated reality, probably most appropriate at more junior levels of training. At a more senior level observation in the real setting is imperative. We also caution for elaborate checklists. Checklists tend to become rote learning objectives and may lead to trivial "unauthentic" communication behavior.

In a review by Boon and Stewart 44 different communication instruments were identified, most of which were unvalidated [36]. We are not going to recommend a specific assessment instrument. We caution, however, for an atomistic and reductionist approach. We iterate the need for holistic judgments that are relevant to shape skilled communication. We strongly recommend using narrative information as a resultant of reflective dialogues between assessor and learner based on direct observations. Given the context-specific and goal-directed nature of medical communication, such reflective dialogues should include residents' reflections on the goals they aimed to achieve during the encounter, which contextual factors influenced the doctor-patient interaction and whether their communication behaviors were appropriate or effective given these goals and context factors. We also advise to train assessors or clinical supervisors on how to give meaningful feedback. Giving feedback is a skill that needs to pay attention to certain do's and don'ts. See Lefroy et al. for a good overview [37]. There is remarkable overlap between the skills that are used for doctor-patient communication and the skills needed for giving good feedback (for example, asking open-ended questions, reflection of feelings, summarizing, checking if the information is understood). The utility of an instrument in unstandardized assessment - such as in direct observation in an authentic setting - lies more in the users of the instrument and the quality of the interaction, than in the "validity" of the instrument itself [38]. Therefore, we should invest more in (the training of) the users, rather than trying to find the best instrument. Whatever instrument is being used, it should be in-line with the objectives of the training program in order to achieve constructive alignment.

By relying on more holistic professional judgment there will be more subjectivity in the assessment. We need to realize, however, that many subjective judgments can give very reliable judgment in the end [38]. The risk of trying to objectify the assessment is trivialization of the learning process and many authors have cautioned for that [38-40]. We tend to think that assessors can be calibrated, but this is an illusion. Assessors construct their own opinions from their own past experience [39]. Rather than trying to calibrate them, it is better to make their opinions and inferences as explicit as possible. From a psychometric perspective two assessors having different opinions is considered to be "noise" in the measurement. But from a learning perspective, different opinions may be very beneficial for the learner. In programmatic assessment the individual data point is not "harnessed" from a psychometric perspective, but rather optimized for learning by giving meaningful feedback. By gathering many data points and through triangulation of the information a rich picture emerges from a learner over time. Once such a picture is achieved, high stake decisions can be taken. These decisions are then taken by an independent committee. These committee decisions based on rich data can be quite robust [41-44].

Because self-assessment is strongly biased [45] and selfdirected learning needs scaffolding [46], programmatic assessment promotes a form of directed self-assessment [47] through coaching or mentoring. Mentoring has shown to have many positive effects in education [48]. In programmatic assessment learners are periodically required to self-analyze, based on the available data and discuss their progress and plans with a mentor. This might also be done for assessing communication. By having regular conversations about learner progress on communication with a trusted person, metacognitive insights will be promoted that again help to further develop one's communication behavior. In this regard, learning communication skills should become part of learners' lifelong personal development. Continuous coaching in the form of these programmatic assessment conversations offers a viable opportunity to support this personal learning process. The teaching and learning of communication then can be regarded a continuous process of transformative learning [49-51].

\section{Discussion and conclusion}

The assessment literature has long been dominated with a psychometric approach [40]. Due to the move towards competency-based education, complex skills needed to be learned and assessed. Communication is one of them. Assessment has moved from this exclusive psychometric orientation to a more learningoriented assessment. Instead of assessment driving learning, now learning is driving assessment. As is clear from the above, we recommend an assessment approach to communication where assessment and learning strongly overlap, that is growth oriented in a longitudinal fashion, focused on personal development, and where at the same time robust decisions can be taken on learner progress. Such an approach will lead to a skilled communication outcome and a versatile and strong clinical tool. In this way communication will make its own contribution to the improvement of health care.

Although the programmatic approach to assessment is conceptually clear, it is not easy to implement. Assessment is strongly associated with a classic summative paradigm. The classic paradigm consists of a modular approach to education, in which each module is completed with an assessment and educational credits are given when each assessment is passed. This summative model can produce quite negative learning styles of rote learning and extrinsic motivation to learn [52]. For many it is quite difficult to think outside this classic paradigm [53]. To move towards programmatic assessment, many stakeholders need to be convinced. Staff development and change management strategies may help, but ultimately it requires a big change in the mindset of the stakeholders.

We are convinced that if we wish to strive for skilled communication, a learner-oriented assessment strategy such as programmatic assessment is needed. The concept has proved itself in many implementations around the world. The research on why and how programmatic research works is ongoing [54]. We hope to see more research on this approach to assessment on how this may facilitate the learning of communication. 


\section{Funding}

This paper did not receive any specific grant from funding agencies in the public, commercial, or not-for-profit sectors.

\section{Declaration of Competing Interest}

None.

\section{References}

[1] J.R. Frank, L.S. Snell, O.T. Cate, E.S. Holmboe, C. Carraccio, S.R. Swing, P. Harris, N.J. Glasgow, C. Campbell, D. Dath, Competency-based medical education: theory to practice, Med. Teach. 32 (8) (2010) 638-645.

[2] S.R. Swing, The ACGME outcome project: retrospective and prospective, Med. Teach. 29 (7) (2007) 648-654.

[3] GMC, Good Medical Practice: Working With Doctors for Patients, (2013).

[4] N. Frederiksen, The real test bias: influences of testing on teaching and learning, Am. Psychol. 39 (3) (1984) 193-202.

[5] J.R. Frank, R. Mungroo, Y. Ahmad, M. Wang, S. De Rossi, T. Horsley, Toward a definition of competency-based education in medicine: a systematic review of published definitions, Med. Teach. 32 (8) (2010) 631-637.

[6] Anonymous, ACGME Outcome Project, (2000). (Accessed 30 October 2003 2003) http://www.acgme.org/Outcome/.

[7] J.R. Frank, D. Danoff, The CanMEDS initiative: implementing an outcomesbased framework of physician competencies, Med. Teach. 29 (7) (2007) 642-647.

[8] J. Merrienboer, P. Kirschner, Ten Steps to Complex Learning. A Systematic Approach to Four-component Instructional Design, Routledge, New York/ London, 2007.

[9] D. Nestel, T. Tierney, Role-play for medical students learning about communication: guidelines for maximising benefits, BMC Med. Educ. 7 (1) (2007) 3.

[10] L. Bokken, J.J. Rethans, A.J. Scherpbier, C.P. van der Vleuten, Strengths and weaknesses of simulated and real patients in the teaching of skills to medical students: a review, Simul. Healthc. 3 (3) (2008) 161-169.

[11] J. van Dalen, E. Kerkhofs, B.W. van Knippenberg-Van Den Berg, H.A. van Den Hout, A.J. Scherpbier, C.P. van der Vleuten, Longitudinal and concentrated communication skills programmes: two dutch medical schools compared, Adv. Health Sci. Educ. Theory Pract. 7 (1) (2002) 29-40.

[12] K. Aspegren, BEME Guide No. 2: teaching and learning communication skills in medicine-a review with quality grading of articles, Med. Teach. 21 (6) (1999) 563-570.

[13] R. Hulsman, W. Ros, J. Winnubst, J. Bensing, Teaching clinically experienced physicians communication skills. A review of evaluation studies, Medical education 33 (9) (1999) 655-668.

[14] W. Veldhuijzen, K. Mogendorff, P. Ram, T. van der Weijden, G. Elwyn, C. van der Vleuten, How doctors move from generic goals to specific communicative behavior in real practice consultations, Patient Educ. Couns. 90 (2) (2013) 170-176.

[15] G. Essers, S. van Dulmen, C. van Weel, C. van der Vleuten, A. Kramer, Identifying context factors explaining physician's low performance in communication assessment: an explorative study in general practice, BMC Fam. Pract. 12 (2011) 138.

[16] K.A. Ericsson, Deliberate practice and the acquisition and maintenance of expert performance in medicine and related domains, Acad. Med. 79 (10 Supplement) (2004) S70-S81.

[17] P. Salmon, B. Young, Creativity in clinical communication: from communication skills to skilled communication, Med. Educ. 45 (3) (2011) $217-226$.

[18] V. van den Eertwegh, C. van der Vleuten, R. Stalmeijer, J. van Dalen, A. Scherpbier, S. van Dulmen, Exploring residents' communication learning process in the workplace: a five-phase model, PLoS One 10 (5) (2015) e0125958.

[19] E. Giroldi, W. Veldhuijzen, K. Geelen, J. Muris, F. Bareman, H. Bueving, T. van der Weijden, C. van der Vleuten, Developing skilled doctor-patient communication in the workplace: a qualitative study of the experiences of trainees and clinical supervisors, Adv. Health Sci. Educ. 22 (5) (2017) $1263-$ 1278.

[20] V. van den Eertwegh, J. van Dalen, S. van Dulmen, C. van der Vleuten, A Scherpbier, Residents' perceived barriers to communication skills learning: comparing two medical working contexts in postgraduate training, Patient Educ. Couns. 95 (1) (2014) 91-97.

[21] E. Giroldi, W. Veldhuijzen, T. de Leve, T. van der Weijden, H. Bueving, C. van der Vleuten, I still have no idea why this patient was here': an exploration of the difficulties GP trainees experience when gathering information, Patient Educ. Couns. 98 (7) (2015) 837-842.

[22] A.N. Kluger, A. DeNisi, The effects of feedback interventions on performance: a historical review, a meta-analysis, and a preliminary feedback intervention theory, Psychol. Bull. 119 (1996) 254-284.

[23] J.M. Van de Ridder, W.C. McGaghie, K.M. Stokking, O.T. Ten Cate, Variables that affect the process and outcome of feedback, relevant for medical training: a meta-review, Med. Educ. 49 (7) (2015) 658-673.
[24] C. Watling, E. Driessen, C.P. Van der Vleuten, L. Lingard, Learning from clinical work: the roles of learning cues and credibility judgements, Med. Educ. 46 (2) (2012) 192-200.

[25] C. Watling, E. Driessen, C.P. Vleuten, M. Vanstone, L. Lingard, Beyond individualism: professional culture and its influence on feedback, Med. Educ. 47 (6) (2013) 585-594.

[26] S. Ramani, K.D. Könings, S. Ginsburg, C.P. van der Vleuten, Twelve tips to promote a feedback culture with a growth mind-set: swinging the feedback pendulum from recipes to relationships, Med. Teach. (2018) 1-7.

[27] S. Ginsburg, K. Eva, G. Regehr, Do in-training evaluation reports deserve their bad reputations? A study of the reliability and predictive ability of ITER scores and narrative comments, Acad. Med. 88 (10) (2013) 1539-1544.

[28] S. Ginsburg, C.P. van der Vleuten, K.W. Eva, The hidden value of narrative comments for assessment: a quantitative reliability analysis of qualitative data, Acad. Med. 92 (11) (2017) 1617-1621.

[29] J.B. Biggs, Enhancing teaching through constructive alignment, High. Educ. 32 (3) (1996) 347-364.

[30] C.P. Van der Vleuten, L.W. Schuwirth, E.W. Driessen, J. Dijkstra, D. Tigelaar, L.K. Baartman, J. van Tartwijk, A model for programmatic assessment fit for purpose, Med. Teach. 34 (3) (2012) 205-214.

[31] C. Van der Vleuten, L. Schuwirth, E. Driessen, M. Govaerts, S. Heeneman, Twelve Tips for programmatic assessment, Med. Teach. 37 (7) (2015) 641-646.

[32] C. Van der Vleuten, B. Verhoeven, In-training assessment developments in postgraduate education in Europe, ANZ J. Surg. 83 (6) (2013) 454-459.

[33] J.R. Kogan, R. Hatala, K.E. Hauer, E. Holmboe, Guidelines: the do's, don'ts and don't knows of direct observation of clinical skills in medical education, Perspect. Med. Educ. (2017) 1-20.

[34] P. Ram, R. Grol, J.J. Rethans, B. Schouten, C. van der Vleuten, A. Kester, Assessment of general practitioners by video observation of communicative and medical performance in daily practice: issues of validity, reliability and feasibility, Med. Educ. 33 (6) (1999) 447-454.

[35] J. Lockyer, Multisource feedback in the assessment of physician competencies, J. Contin. Educ. Health Prof. 23 (2003) 2-10.

[36] H. Boon, M. Stewart, Patient-physician communication assessment instruments:: 1986 to 1996 in review, Patient Educ. Couns. 35 (3) (1998) 161-176.

[37] J. Lefroy, C. Watling, P.W. Teunissen, P. Brand, Guidelines: the do's, don'ts and don't knows of feedback for clinical education, Perspect. Med. Educ. 4 (6) (2015) 284-299.

[38] C.P. Van der Vleuten, L.W. Schuwirth, F. Scheele, E.W. Driessen, B. Hodges, The assessment of professional competence: building blocks for theory development, Best Pract. Res. Clin. Obstet. Gynaecol. 24 (6) (2010) 703-719.

[39] M.J.B. Govaerts, C.P.M. Van der Vleuten, Validity in work-based assessment: expanding our horizons, Med. Educ. 47 (12) (2013) 1164-1174.

[40] B. Hodges, Assessment in the post-psychometric era: learning to love the subjective and collective, Med. Teach. 35 (7) (2013) 564-568.

[41] E. Driessen, C. van der Vleuten, L. Schuwirth, J. van Tartwijk, J. Vermunt, The use of qualitative research criteria for portfolio assessment as an alternative to reliability evaluation: a case study, Med. Educ. 39 (2) (2005) 214-220.

[42] L.H. de Jong, H.G. Bok, W.D. Kremer, C.P. van der Vleuten, Programmatic assessment: Can we provide evidence for saturation of information? Med. Teach. (2018) 1-5.

[43] A. Oudkerk Pool, M.J. Govaerts, D.A. Jaarsma, E.W. Driessen, From aggregation to interpretation: how assessors judge complex data in a competency-based portfolio, Adv. Health Sci. Educ. (2017) 1-13.

[44] K.E. Hauer, Ot. Cate, C.K. Boscardin, W. Iobst, E.S. Holmboe, B. Chesluk, R.B. Baron, P.S. O'Sullivan, Ensuring resident competence: a narrative review of the literature on group decision making to inform the work of clinical competency committees, J. Grad. Med. Educ. 8 (2) (2016) 156-164.

[45] K.W. Eva, G. Regehr, Self-assessment in the health professions: a reformulation and research agenda, Acad. Med. 80 (10) (2005) S46-S54.

[46] A.B. de Bruin, T. van Gog, Improving Self-Monitoring and Self-Regulation: From Cognitive Psychology to the Classroom, Elsevier, 2012.

[47] J. Sargeant, K. Mann, C. van der Vleuten, J. Metsemakers, "Directed" selfassessment: practice and feedback within a social context, J. Contin. Educ. Health Prof. 28 (1) (2008) 47-54.

[48] E.W. Driessen, K. Overeem, Mentoring, in: K. Walsh (Ed.), Oxford Textbook of Medical Education, Oxford University Press, Oxford, 2013, pp. 265-284.

[49] S. Jarvis-Selinger, D.D. Pratt, G. Regehr, Competency is not enough: integrating identity formation into the medical education discourse, Acad. Med. 87 (9) (2012) 1185-1190.

[50] E. Taylor, Analyzing research on transformative learning theory, in: J.A. Mezirow (Ed.), Learning as Transformation: Critical PerspEctives on a Theory in Progress, Jossey-Bass, San Fransisco, 2000, pp. 285-328.

[51] D.A. Kolb, R.E. Boyatzis, C. Mainemelis, Experiential learning theory: previous research and new directions, Perspectives on thinking, learning, and cognitive styles 1 (8) (2001) 227-247.

[52] F.J. Cilliers, L.W. Schuwirth, H.J. Adendorff, N. Herman, C.P. van der Vleuten, The mechanism of impact of summative assessment on medical students' learning, Adv. Health Sci. Educ. Theory Pract. 15 (5) (2010) 695-715.

[53] C.J. Harrison, K.D. Konings, L.W.T. Schuwirth, V. Wass, C.P.M. van der Vleuten, Changing the culture of assessment: the dominance of the summative assessment paradigm, BMC Med. Educ. 17 (1) (2017) 73.

[54] C. Van der Vleuten, S. Heeneman, S. Schut, Programmatic assessment: an avenue to a different assessment culture, R. Yudkowski, Y. Park, S. Downing Assessment in health professions education, Routledge, in press. 